\title{
Evaluation of surgical-orthodontic treatments on impacted mandibular canines
}

\author{
Mutan-Hamdi Aras ${ }^{1}$, Koray Halicioğlu ${ }^{2}$, Muhammed-Selim Yavuz ${ }^{3}$, Murat Çağlaroğlu ${ }^{4}$ \\ ${ }^{1}$ Assistant Professor, DDs, PhD. Department of Oral and Maxillofacial Surgery, Faculty of Dentistry, Gaziantep University, \\ Gaziantep, Turkey \\ ${ }^{2}$ Orthodontic private practice, Bolu, Turkey \\ ${ }^{3}$ Assistant Professor, DDs, PhD. Department of Oral and Maxillofacial Surgery, Faculty of Dentistry, Ataturk University, Erzu- \\ rum, Turkey \\ ${ }^{4}$ Assistant Professor, DDs, PhD. Department of Orthodontics, Faculty of Dentistry, Kırıkkale University, Kırıkkale, Turkey
}

Correspondence:

Department of Oral and Maxillofacial Surgery,

Faculty of Dentistry, Gaziantep University.

Gaziantep, 27310

Turkey

mutanhamdi@hotmail.com

\author{
Aras MH, Halicioğlu K, Yavuz MS, Cağlaroğlu M. Evaluation of surgi- \\ cal-orthodontic treatments on impacted mandibular canines. Med Oral \\ Patol Oral Cir Bucal. 2011 Nov 1;16 (7):e925-8. \\ http://www.medicinaoral.com/medoralfree01/v16i7/medoralv16i7p925.pdf

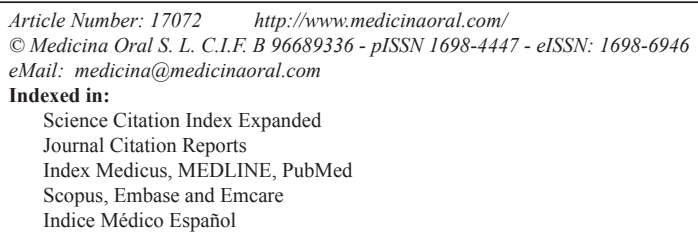

Received: 22/04/2010

Accepted: $14 / 11 / 2010$

\begin{abstract}
Objective: The aim of the study was to evaluate patients treated for impacted mandibular canines through a combined surgical and orthodontic approach.

Study Design: The cases which were made button operations of impacted mandibular canines were selected from 5100 panoramic radiographs taken from patients who made use of our oral and maxillofacial surgery services between January 1998 to April 2006. All of these selected patients were assessed radiographically. Pertinent information such as sex, age at the time of surgery, site of the unerupted tooth, space availability and any other associated pathoses were also recorded. These patients were called again, and the condition of the mandibular canines was evaluated with panoramic radiographs. If the tooth erupted in the right position and it was functional and asymptomatic, we assumed the treatment to be successful clinically.

Results: In the present study, from 5100 patients, 69 patients had impacted mandibular canines and only 21 patients' teeth (a total of 23 teeth) were treated orthodontically. Sixteen impacted mandibular canine teeth of 14 patients erupted successfully. Two impacted canine were extracted, and only one canine tooth was transplanted to the normal position. Four patients ended the treatment because of failure of eruption.

Conclusion: If a mandibular canine tooth is impacted, not only is surgical exposure sufficient but also traction force must be applied orthodontically after the surgical exposure. In addition, age influences the success of the treatment on impacted mandibular canine teeth more than the position and impaction level of the teeth.
\end{abstract}

Key words: Cuspid, tooth impacted, orthodontic extrusion, mandibular canine, forced eruption. 


\section{Introduction}

In human dentition, maxillary and mandibular canines are very important teeth from the point of aesthetic and function (1-3). The maxillary canine teeth have the longest period of development, the deepest area of development and the most devious path to travel to full occlusion (4). For this reason, the most frequently impacted tooth in the anterior region of the mouth is the maxillary canine (5). The prevalence of impacted maxillary canines is $0.9-2.2 \%$, but mandibular canine impaction occurs less frequently (6-9).

The treatment alternatives are similar for the management of mandibular canines, and the current treatment options are as follows:

1. No treatment. The deciduous canine may have good root length and may be esthetically acceptable. Alternatively, the deciduous canine may have exfoliated earlier and the canine space closed spontaneously leaving a good premolar-to-incisor contact point. The canine should, however, be observed to ensure that no resorption of adjacent teeth occurs. In many ways removing the impacted canine is probably better to prevent resorption.

2. Extraction of the mandibular canine teeth and space closure. This may be a difficult orthodontic treatment depending on the size of the residual space and the inclination of adjacent teeth.

3. Transplantation. This procedure is relatively quick but has an uncertain long-term prognosis.

4. Prosthetic or restorative treatment.

5. Surgical exposure followed by forced eruption with orthodontic treatment $(3,5,10)$.

In the past, several techniques have been described for eruption of the unerupted permanent teeth. Azaz et al. (11) proposes that these can be classified into three categories. [1]The first procedure involves the surgical exposure of the crown of the impacted teeth for eruption. This involves excision of all soft and hard tissues around the crown of the unerupted canine, including the dental sac, to maintain a patent channel around the crown and normal eruptive path into the oral cavity. [2] The other procedure involves the application of attachment to the partially exposed crown. In this situation, an orthodontist is able to apply active directional traction. [3]The last technique involves surgical repositioning of the severely malposed or impacted tooth from its original position to an ideal position for eruption. This is accomplished by surgically exposing the unerupted crown and removing sufficient bone to create an adequate channel through which the tooth is gently luxated and rotated into the desired position (11). Either an open or closed surgical approach can be used to uncover the crown of an impacted tooth and place an orthodontic attachment. Various attachments are used to erupt impacted teeth, including threaded pins, cast gold inlays, gold cups with cleats, wire ligation, bonded attachment, bands and extracoronal caps; some are more damaging than others to the periodontium, the impacted tooth or adjacent teeth (12).

This article presents a retrospective study of the management of impacted mandibular canines treated with a combined surgical and orthodontic approach.

\section{Materials and Methods}

We designed a retrospective cohort study composed of 5100 panoramic radiographs taken from patients who were presented to our department between January 1998 to April 2006. All of the cases related to button operations of impacted mandibular canines were selected (21 patients). These patients were assessed radiographically. Pertinent information such as sex, age at the time of surgery, site of the unerupted tooth, space availability and any other associated pathoses were also recorded. Patients which had not taken pre or post-treatment radiographs were excluded from study.

During surgery, a facial flap was raised in all cases by a maxillofacial surgeon. Bone was removed if necessary. An attachment (button) was bonded onto the crown of the tooth. The flap was replaced to its original position with a chain or wire extending from the attachment into the oral cavity.

If necessary, sufficient space was created for the impacted canine in the mandibular arch orthodontically. An elastic thread was then attached from the silver chain to the fixed orthodontic appliances. Orthodontic force was applied in order to erupt the tooth after tissue healing. The tooth was then actively extruded orthodontically. In some cases, premolars had been extracted to create space for the canines.

All of these patients were called again for control, and the condition of the mandibular canines was evaluated with panoramic radiographs. If the tooth erupted in the right position and it was functional and asymptomatic, we assumed the treatment to be successful clinically.

\section{Results}

From all of the 5100 patients, 69 patients had impacted mandibular canines and only 21 patients' (ages 12-24) teeth were treated with forced eruption by orthodontic treatment. The mean age of the patient's teeth that erupted successfully were 15.1, and the mean age of the patients' teeth that could not erupt were 19.9. Only in two patients were the canines bilateral, the others were unilateral, and in total 23 canine teeth were evaluated. Eleven canines impacted on the left side, 12 on the right. Twelve patients were female, and nine patients were male. In 13 instances inadequate space was the probable factor of impaction. Only five deciduous canines had retained, and there were no supernumerary teeth or any pathology in any (all) cases. 


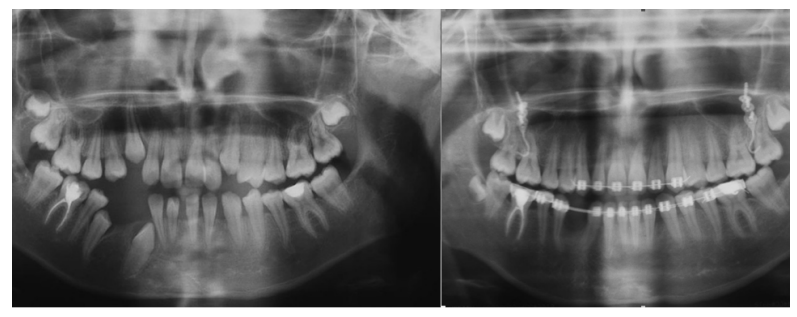

Fig. 1A-B. Pre and post treatment radiograph of the successfully erupted canine and premolar.

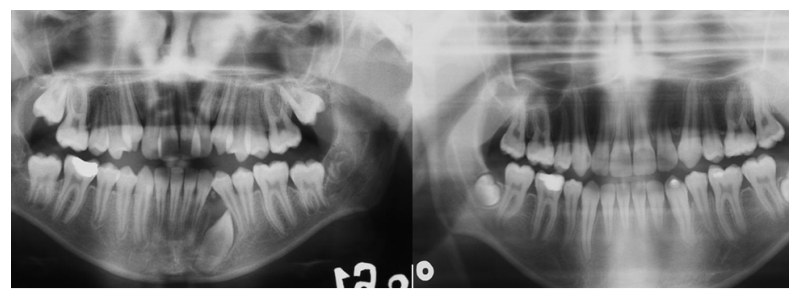

Fig. 2A-B. Panoramic radiograph of the mandibular canine before and after forced eruption.

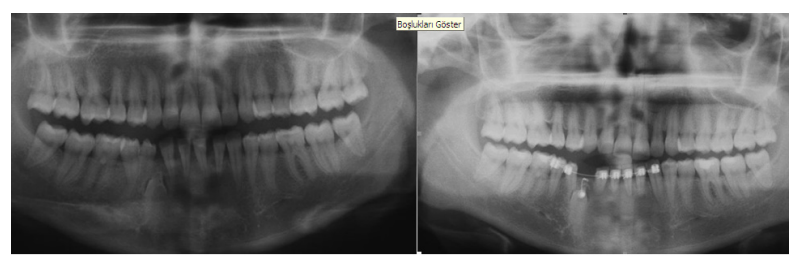

Fig. 3A-B. Before treatment of the impacted canine tooth with ankylosis, and failure of the forced eruption after 18 months.

Sixteen impacted mandibular canine teeth of 14 patients erupted successfully (Fig. 1A-B, Fig. 2A-B). Two impacted canine were extracted, (Fig. 3A-B) and only one canine tooth was transplanted to the normal site. Four patients ended the treatment because of the failure of forced eruption.

\section{Discussion}

Many authors have speculated about the cause of impacted mandibular canines (11). These are inadequate space, supernumerary teeth, premature loss of the deciduous dentition, retention of the deciduous canine, excessive crown length, hereditary factors, functional disturbances of the endocrine glands, tumors, cysts and trauma (1,13-16). Insufficient space was the most common factor interfering with the normal eruption of teeth in general (11). In the mandible, mild crowding in the buccal segments led to impaction of the lower second premolars, frequently complicated by impaction of the lower third molars. Rarely, mandibular canine impactions occur (17). We think that inadequate space was the main factor of canine impaction in our 15 instances.
However in six instances, retained decidduous canine and inadequate space were the main contributing factors. There were no supernumerary teeth or any pathology in the other cases.

All attempts to expose and align unerupted canines are long and expensive. Careful patient selection and preparation therefore is essential as is cooperation between the orthodontist and the oral surgeon (5). The appropriate management of impacted mandibular canines is carried out in consultation with an orthodontist. The method of surgical exposure followed by forced extrusion orthodontically has the best long-term prognosis (18). However, during this procedure, damage to adjacent structures (19) and periodontal health of the unerupted canine should be considered. In this study, we evaluated the eruption and treatment method of 23 impacted mandibular canines. We reported that $16 \mathrm{im}-$ pacted mandibular canine teeth of 14 patients erupted successfully. Two impacted teeth were extracted, and only one canine tooth was transplanted to the normal site. Four patients ended the treatment because of failure of eruption.

Azaz et al. (11) states that forced eruption in four teeth from 31 impacted teeth applies a traction force resulting in failure. Some authorities believe that the age of a patient is a very helpful factor in predicting the success of the proposed tooth movement (20). Orton et al. (21) claims that treatments starting after the end of a pubertal growth spurt are likely to be protracted. In our study, the mean age of patients treated successfully was 15.5 and the mean age of patients who could not obtain eruption was 19.9. A high mean age may be the reason of the failure.

Among orthodontic patients, the number of women is higher than men (1). This sex predilection was the same in our study. Out of a total of 21 patients who were treated orthodontically, 12 were female and nine were male. If there was any pathology such as odontoma or any supernumerary tooth, the first procedure might have been sufficient. But in all of our cases, any pathology or supernumerary teeth were not related to impacted canines. Observed morphologic changes in the root formation after the treatments illustrated two basic types: premature completion of root formation (or dwarfed roots) and dilacerations. Azaz et al. (11) reports that dwarfed roots have been seen in eight instances, seven of which were associated with repositioned teeth. In addition, he reports that dilacerations of the roots were seen in eight cases, three of which were associated with exposure only and four of which were associated with repositioned teeth (11). In our study, any sequelae did not appear in the treated teeth. Probably, because we did not use a repositioning procedure this condition was not seen in any of our cases.

Root resorption is a well-recognized complication of 
impacted canines. Complicating factors that the clinician must be aware of and look for include evidence of root resorption of the adjacent teeth, because root resorption may modify the treatment plan and strategy. If it is possible and practical, the impacted tooth should be moved away from the roots of the adjacent teeth (22). In this study, tooth resorption only occurred in two cases. But, root resorption started before treatment in both cases.

Since forced eruption of impacted canines provides the best long-term results, intervention with a surgical attachment of an orthodontic button or bracket should be implemented (23). In conclusion, if a mandibular canine tooth is impacted, not only is surgical exposure sufficient but also traction force must be applied orthodontically after the surgical exposure. In addition, age influences the success of the treatment on impacted mandibular canine teeth more than the position and impaction level of the teeth.

\section{References}

References with links to Crossref - DOI

1. Joshi MR. Transmigrant mandibular canines: a record of 28 cases and a retrospective review of the literature. Angle Orthod. 2001;71:12-22.

2. Aras MH, Büyükkurt MC, Yolcu U, Ertaș U, Dayi E. Transmigrant maxillary canines. Oral Surg Oral Med Oral Pathol Oral Radiol Endod. 2008;105:e48-52.

3. Buyukkurt MC, Aras MH, Caglaroglu M, Gungormus M. Transmigrant mandibular canines. J Oral Maxillofac Surg. 2007;65:2025-9.

4. Ferguson JW. Management of the unerupted maxillary canine. $\mathrm{Br}$ Dent J. 1990;169:11-7.

5. McDonald F, Yap WL. The surgical exposure and application of direct traction of unerupted teeth. Am J Orthod. 1986;89:331-40.

6. D’Amico RM, Bjerklin K, Kurol J, Falahat B. Long-term results of orthodontic treatment of impacted maxillary canines. Angle Orthod. 2003;73:231-8.

7. Aydin U, Yilmaz HH, Yildirim D. Incidence of canine impaction and transmigration in a patient population. Dentomaxillofac Radiol. 2004;33:164-9.

8. Alaejos-Algarra C, Berini-Aytes L, Gay-Escoda C. Transmigration of mandibular canines: report of six cases and review of the literature. Quintessence Int. 1998;29:395-8.

9. Yavuz MS, Aras MH, Büyükkurt MC, Tozoglu S. Impacted mandibular canines. J Contemp Dent Pract. 2007;8:78-85.

10. Buyukkurt MC, Aras MH, Caglaroglu M. Extraoral removal of a transmigrant mandibular canine associated with a dentigerous cyst. Quintessence Int. 2008;39:767-70.

11. Azaz B, Steiman Z, Koyoumdjisky-Kaye E, Lewin-Epstein J. The sequelae of surgical exposure of unerupted teeth. J Oral Surg. 1980;38:121-7.

12. Frank CA, Long M. Periodontal concerns associated with the orthodontic treatment of impacted teeth. Am J Orthod Dentofacial Orthop. 2002;121:639-49.

13. Milano M, Barrett L 2nd, Marshall E. Extraction of a horizontally impacted mandibular canine through a genioplasty approach: report of a case. J Oral Maxillofac Surg. 1996;54:1240-2.

14. Camilleri S, Scerri E. Transmigration of mandibular canines--a review of the literature and a report of five cases. Angle Orthod. 2003;73:753-62.

15. Mitchell L. Displacement of a mandibular canine following fracture of the mandible. Br Dent J. 1993;174:417-8.

16. Brezniak N, Ben-Yehuda A, Shapira Y. Unusual mandibular canine transposition: a case report. Am J Orthod Dentofacial Orthop. 1993;104:91-4.
17. McBride LJ. Traction--a surgical/orthodontic procedure. Am J Orthod. 1979;76:287-99.

18. Gensior AM, Strauss RE. The direct bonding technique applied to the management of the maxillary impacted canine. J Am Dent Assoc. 1974;89:1332-7.

19. Ericson S, Kurol J. Incisor resorption caused by maxillary cuspids. A radiographic study. Angle Orthod. 1987;57:332-46.

20. Machen DE. Legal aspects of orthodontic practice: risk management concepts. The impacted canine. Am J Orthod Dentofacial Orthop. 1989;96:270-1.

21. Orton HS, Garvey MT, Pearson MH. Extrusion of the ectopic maxillary canine using a lower removable appliance. Am J Orthod Dentofacial Orthop. 1995;107:349-59.

22. Kuftinec MM, Shapira Y. The impacted maxillary canine: II. Clinical approaches and solutions. ASDC J Dent Child. 1995;62:32534.

23. Crawford LB. Four impacted permanent canines: an unusual case. Angle Orthod. 2000;70:484-9. 